\title{
LAPAROSCOPIC DIRECTED MINILAPAROTOMY FOR THE MANAGEMENT OF DISTURBED ECTOPIC PREGNANCY. IS IT WORTHY?
}

\author{
Hatem AbuHashim, M.D; Mohamed El-Negery, M.D; Kamal Anwar, M.D; \\ Rafat Abd El-Fatah, M.D and Mohamed Nezar, M.D. \\ Department of Obstetrics and Gynecology, Mansoura Faculty of Medicine,
}

Mansoura University, Egypt

\section{ABSTRACT}

Design : A comparative clinical trial.

Study objective : To compare the efficacy, appropriateness and cost effectiveness of salpingectomy carried out by laparoscopic directed minilaparotomy for the management of disturbed ectopic pregnancy in haemodynamically stable patients, with Laparoscopic salpingectomy carried out by triple-loop technique and that by bipolar clectrosurgical technique.

Setting : Operative endoscopy unit in Mansoura University Hospitals from June 2002 till March 2004.

Subjects: 48 women with clinical suspicion of disturbed ectopic pregnancy confirmed by $\beta$ HCG and transvaginal ultrasound scan (TVS). All patients were hacmodynamically stable.

Intervention: All cases were subjected to initial laparoscopic evaluation. 2 Cases were excluded; one converted to laparotomy being istmic pregnancy and the other one was secured totally by laparoscopy being fimbrial pregnancy. The remaining 46 women with confirmed ampullary pregnancy were subjected to laparoscopic management as follows; 13 cases underwent laparoscopic salpingectomy carried out by triple - loop technique , 11 cases by bipolar electrosurgical technique and the remaining 22 cases by laparoscopic directed minilaparotomy.

Results : Salpingectomy carried out by laparoscopic directed minilaparotomy was compared with the other 2 groups (triple-loop technique and bipolar electrosurgical technique) concerning its surgical feasibility, operative time, safety, cost effectiveness, analgesia requirements, recovery time/ return to normal and cosmetic results.

Salpingectomy carried out by laparoscopic directed minilaparotomy enjoys all the advantages of minimally invasive surgery including good cosmetic results, reduced postoperative analgesia requirements and a quicker return of patients to their normal activities. With respect to these, it competes favourably with both laparoscopic salpingectomy by triple-loop technique and bipolar electrosurgical one. However, it is more cost effective than the former and more safer than the latter. Also, training of surgeons and acquisition of the necessary skills takes shorter than for the other tcchniques.

Conclusion : Salpingectomy carried out by laparoscopic directed minilaparotomy for the management of disturbed ectopic ampullary pregnancy in haemodynamically stable patients is a simple, safe, versatilc and cost effective technique. It may be of benefit and could be offered as an alternative option in circumstances with limited resources and when electrosurgery is not preferred or the clectrosurgical unit is out of function.

Keywords : Ectopic pregnancy, tubal pregnancy, laparoscopy, laparoscopic salpingectomy, laparoscopic salpingotomy.

\section{INTRODUCTION}

The management of ectopic pregnancy has undergone a revolution in the past few decades.
Evidence suggests that the incidence of ectopic pregnancy has been rising. In the USA, the incidence of ectopic pregnancy/1000 pregnancies increased fourfold from 1970 to 1992 (4.5/1000 to

Corresponding author: Hatem Abu Hashim, MD, Lecturer of OB/GYN, Dakahlia Governorate, Mansoura P.O.Box 218, Egypt

Email: hatem_ah@hotmail.com 
18/1000). Furthermore, ectopic pregnancy accounted for $9 \%$ of all maternal deaths in USA from 1990 to $1992^{(1,2)}$. In the UK, the incidence has been doubled from 4.9 to $11.1 / 1000$ pregnancies during 1973 to 1999 , while mortality has decreased from 16 to $4 / 1000(3,4)$. During 1997-1999, ectopic pregnancy accounted for $12.2 \%$ of all maternal deaths and remained the leading cause of death in the first trimester ${ }^{(4)}$. Even during the last triennium (2000-2002), the mortality rate for deaths from ectopic pregnancies has not declined ${ }^{(5)}$.

The clinical presentation of ectopic pregnancy is variable. This variation depends upon the time when the diagnosis is made. With the present attitude of "think ectopic " in any woman of childbearing age who complains of abdominal pain and with high resolution ultrasonography and beta human chorionic gonadotropin ( $\beta \mathrm{HCG})$ estimations, the diagnosis of ectopic pregnancy can be made with a high degree of certainty. However, laparoscopy remains the final definitive diagnostic tool ${ }^{(6-8)}$.

Diagnostic laparoscopy enables not only visualisation of the ectopic pregnancy but also recognition of its site, its size, the state of the tube containing the ectopic sac, whether it is ruptured or intact, the condition of the contralateral tube as well as the presence and volume of the haemoperitoneum ${ }^{(6-8)}$.

Disturbed tubal ectopic pregnancy could be managed by either laparotomy or operative laparoscopy according to the skill of the surgeon involved, the clinical condition and future fertility requirements of the woman (7-9). However, Recently according to the Royal College of Obstetricians and Gynaecologists of London (RCOG) guidelines, there is a strong evidence that a laparoscopic approach to the surgical management of tubal pregnancy, in the haemodynamically stable patient, is preferable to an open approach (grade A recommendation) (9). Furthermore, in the presence of a healthy contralateral tube, there is no clear evidence that salpingotomy should be used in preference to salpingectomy (grade $\mathrm{B}$ recommendation) ${ }^{(9)}$.

Laparoscopic salpingectomy could be done by bipolar electrosurgical technique or triple loop technique ${ }^{(7,10-12)}$.

In the bipolar electrosurgical technique, the tube is grasped, electrodessicated and divided with scissors first at the level of the uterotubal junction, then at the level of the tubo-ovarian ligament. Finally, the mesosalpinx is electrodessicated and divided in a series of burns and cuts until complete excision of the tube has been achieved ${ }^{(7,8,11)}$. In the triple loop technique, three Roeder loops are used to ligate the mesosalpinx and the tube proximal to the gestational sac is then, divided with scissors. Triple ligation is utilized to ensure satisfactory haemostasis and minimize slippage $(7,8,10,12)$. Wherease some authors $(10,11)$ routinely left an intraperitonaeal drain placed in the pouch of Douglas for 24 hours or longer, others did not leave it $(7,13)$.

Provided the affected tube can be shown to be free by gentle manipulation, access can be gained by minilaparotomy performed by experienced laparoscopists, on occasions, when necessary laparoscopic instruments are not available ${ }^{(7)}$.

Minilaparotomy incision was also utilized during laparoscopic myomectomy, a technique known as laparoscopically assisted myomectomy, useful for cases with multiple myomas/or deep intramural myomas requiring multilayer closure. This technique entails laparoscopic removal of the 
myomas and multilayer suturing of the uterine defect via a minilaparotomy incision (14).

\section{AIM OF THE WORK}

To compare the efficacy, appropriateness and cost effectiveness of salpingectomy carried out by laparoscopic directed minilaparotomy for the management of disturbed ectopic pregnancy in haemodynamically stable patients, with laparoscopic salpingectomy carried out by triple-loop technique or that by bipolar electrosurgical technique.

\section{PATIENTS \& METHODS}

Setting: Operative endoscopy unit in Mansoura University Hospitals form June 2002 till March 2004 .

Subjects: 48 women with clinical suspicion of disturbed ectopic pregnancy confirmed by $\beta \mathrm{HCG}$ and TVS. All patients were haemodynamically stable.

Intervention: All our patients were fully counselled and informed consents were obtained, Initial laparoscopic evaluation was carried out. Two Cases were excluded; one converted to laparotomy being isthmic pregnancy and the other one was secured totally by laparoscopy being fimbrial pregnancy. The remaining 46 women with confirmed ampullary pregnancies were divided into 3 groups, subjected to laparoscopic management as follows; first group: $\mathrm{N}=13$, underwent laparoscopic salpingectomy carried out by triple-loop technique. Second group: $\mathrm{N}=11$, by bipolar electrosurgical technique and the third group: $\mathrm{N}=22$ by laparoscopic directed minilaparotomy.

In the bipolar electrosurgical technique, the tube is grasped, electrodessicated and divided with scissors first at the level of the uterotubal junction, then at the level of the tubo-ovarian ligament. Finally, the mesosalpinx is electrodessicated and divided in a series of burns and cuts until complete excision of the tube has been achieved. In the triple loop technique, three Roeder loops ( 0 chromic) are used to ligate the mesosalpinx and the tube proximal to the gestational sac. Then, divided with scissors. A pelviderain is obligatory.

Laparoscopic Directed Minilaparotomy:

The laparoscope is usually introduced intraumbilically. The second puncture is normally placed suprapubically in the midline one inch above the symphysis pubis, with a $5 \mathrm{~mm}$ trocar and cannula that will accommodate instruments used both during the preliminary assessment and subsequent surgery, The third portal will be placed in one or other flank.

the first step is to ensure that the affected tube is free by gentle manipulation after peritoneal lavage has emoved all blood clots and the contralateral tube proved to be healthy. Then, the grasping forceps is inserted through the suprapubic trocar to hold the affected tube proximal to the ectopic gestational sac, thereby steadying it.

The next step is to withdraw the grasper upwards until it reaches the anterior abdominal wall at the site of the suprapubic trocar. While the patient is left in the Trendelenberg position, the uterine cannula placed in the cervix is used to maneuver the uterine fundus forwards and upwards, thus assisting the grasper pulling the affected tube upwards.

Now, the minilaparotomy incision is made by extending the original suprapubic incision on both sides. The length of this minilaparotomy incision is 
usually $3-4 \mathrm{~cm}$ determined by prior pelvic findings and especially the depth of the patient's subcutaneous adipose layer. The subcutaneous fat is dissected bluntly, the rectus sheath is incised transversely, the recti are separated and the peritoneum is opened. Then $\mathrm{Co}^{2}$ will escape and the affected tube is delivered out via the incision together with the grasper forceps and the $5 \mathrm{~mm}$ trocar which are removed and 2 or 3 Babcock forceps are used insead to catch the tube.

The definitive surgery is performed entailing excision of the ampullary pregnancy after placing Vicryl stitch Number 1 twice proximal to the gestational sac. The remaining tubal stump is dropped inside the peritoneal cavity and the minilaparotomy incision is closed.

Creation of pneumoperitoneum again via the principal umbilical trocar and final inspection of the tubal stump are carried out followed by meticulous pelvic lavage via the third portal placed in the flank to prevent the later formation of adhesions. Routine insertion of a pelvidrain has not been our practice.

All patients were offered prophylactic antibiotics, such as a single dose of first-generation cephalosporin or ampicillin, to reduce the risk of any postoperative infections. Post-operative analgesia included Tenoxicam (Epicotil $\left.{ }^{(}\right)$rectal suppositiories and tramadol $\left(\right.$ Tramal $^{(\circledR)}$ ) intramuscular injection when needed.

All women were discharged within 24 hours after the operation and reviewed after one and 6 weeks .

Salpingectomy carried out by Laparoscopic directed minilaparotomy was compared with the other 2 groups; triple-loop technique and bipolar electrosurgical technique conceming its surgical feasibility, operative time, safety, cost effectiveness, analgesia requirements, recovery time, return to normal and cosmetic results.

\section{Statistics :}

Results were tabulated and analyzed on an IBM personal computer using Microsoft excel 2002 software on windows XP. Continuous data were expressed as Mean $\pm \mathrm{SD}$. Comparison between the mean values of demographic data, operative time and length of hospital stay in the laparoscopic directed minilaparotomy group and the mean values for those in each of the other two groups was done using the paired Student's t-test. A "P" value of $<0.05$ was considered statistically significant.

\section{RESULTS}

The study incorporated 46 haemodynamically stable patients with confirmed disturbed ampullary pregnancy who underwent laparoscopic salpingectomy as follows; first group: $\mathrm{N}=13$, underwent laparoscopic salpingectomy carried out by triple-loop technique. Second group : $N=11$, by bipolar electrosurgical technique and the third group: $\mathrm{N}=22$ by laparoscopic directed minilaparotomy.

Table (I) shows comparison of the demographic data of patients included in the study concerning their age, gravidity, parity, weight $(\mathrm{Kgm})$ height $(\mathrm{cm})$ and Body Mass Index (BMI) in each group, demonstrating the mean value and range in each item. All differences between laparoscopic directed minilaparotomy group patients and those in each of the other two groups were statistically insignificant $(P>0.05)$.

Table (II) shows comparison between the laparoscopic directed minilaparotomy technique and the other two techniques, concerning operative 
time expressed in minutes calculated from the start of anaesthesia, length of hospital stay expressed in hours calculated from termination of the procedure till discharge. All differences between laparoscopic directed minilaparotomy technique and each of the other two techniques were statistically insignificant (P>0.05).

No intraoperative or postoperative complications were reported in any group.

Figure (1) shows comparison of cost per patient and total cost calculated in Egyptian pounds (L.E.) between laparoscopic directed minilaparotomy and triple-loop technique, where the latter costs 255 L.E./patient (85 L.E./one endoloop), versus only 25 L.E/patient for the former. Thus, total cost for the laparoscopic directed minilaparotomy $(\mathrm{N}=22)$ was 550 L.E. versus 3315 L.E. for the triple-loop technique $(\mathrm{N}=13)$.

\section{DISCUSSION}

During the last decade, the management of ectopic pregnancy has undergone a revolution. Compared to laparotomy, laparoscopic surgery carried out by experienced operators is relatively simple to perform, the results are gratifying and cost and recovery times are demonstrably reduced. The subsequent reproductive outcomes were similar in both ${ }^{(7,15-17)}$.

Nowadays, there is limited room for the non-evidence based personal opinions and according to the RCOG guidelines, there is a strong evidence that a laparoscopic approach to the surgical management of tubal pregnancy, in the haemodynamically stable patient, is preferable to an open approach (grade $A$ recommendation) and of course laparotomy is indicated in the presence of haemodynamic instability (grade $\mathrm{C}$ recommendation) ${ }^{(9)}$.

Furthermore, in the presence of a healthy contralateral tube, there is no clear evidence that salpingotomy should be used in preference to salpingectomy (grade B recommendation) ${ }^{(9)}$. As subsequent evaluation of reproductive outcomes in both groups revealed that subsequent intrauterine pregnancy rates were similar but there was a trend towards higher subsequent ectopic pregnancy in the salpingotomy group (18-24). Although some studies suggested that there may be a higher subsequent intrauterine pregnancy rate in the salpingotomy group, yet the magnitude of this benefit may be small ${ }^{(25)}$. Also, the potential need for further treatment for persistent trophoblast is a problem occurring after salpingotomy rather than following salpingectomy ${ }^{(22,25-29)}$.

In our experience, the skill needed to perform laparoscopic directed minilaparotomy for the management of disturbed ectopic ampullary pregnancy is comparable to laparoscopic salpingectomy carried out by triple-loop and bipolar electrosurgical technique and could be used on occasions, when the neccessary laparoscopic instruments are not available; an opinion that is supported by others ${ }^{(7)}$. The low learning curve makes the procedure accessible to surgeons with basic or intermediate laparoscopic skills i.e. level 1 and 2 according to RCOG working party ${ }^{(30)}$.

In our study, laparoscopic directed minilaparotomy competes favourably with both Laparoscopic salpingectomy by triple-loop technique and bipolar electrosurgical as the operative time was similar between the groups $(\mathrm{P}>$ 0.05 ). All women were disharged within 24 hours after the operation and all differences in the length of hospital stay between the groups were statistically insignificant $(P>0.05)$. Post-operative 
analgesic requirements were similar in all groups including Tenoxicam Epicotic $^{(0)}$ ) rectal supposttories and tramadol $\left(\right.$ Tramal $\left.^{(\circledR)}\right)$ intra-muscular injection when needed.

Actually, this may be attributed to: the small size of the incision, the lack of bowel manipulation, along with gentle handling of tissues. Our results are comparable to that reported by other studies in which the minilaparotomy approach was associated with reduced postoperative discomfort and analgesia requirement as well as prompt mobilization of the patient and discharge from the surgicenter within 4-24 hours, with subsequent return to normal activity almost as rapidly as those who underwent laparoscopic surgery ${ }^{(31)}$.

No intraoperative or postoperative complications were encountered. This could be attributed to proper case selection as well as proper training since retrospective studies of the laparoscopic management of ectopic pregnancy report a low rate of intraoperative and postoperative complications and demonstrate that surgery can be safely undertaken by appropriately trained clinical staff ${ }^{(32,33)}$.

Insertion of a pelvidrain has not been our practice, since excision of the ampullary pregnancy after placing vicryl stitch Number 1 twice proximal to the gestational sac was secured completely externally under vision is each case, followed by inspection of the tubal stump later on. An opinion that is supported by others $(7,13)$. While routine insertion of a pelvidrain is mandatory in cases of laparoscopic salpingectomy carried out by triple-loop and bipolar and electrosurgical techniques $^{(10,11)}$.

As shown from figure (1), laparoscopic directed minilaparotomy is more cost-effective than the triple-loop technique, where th latter costs 255
L.E./patient (85 L.E./one endoloop) versus only 25 L.E./patient for the former.

Also, laparoscopic directed minilaparotomy is more safe than the electrosurgical technique especially on the ovary as the high frequency current, even with the use of bipolar electrosurgery may lead to uncontrolled destruction of ovarian vessels, nerves and even tissues. So endocoagulation may be used instead of electrosurgery $(7,10,12)$.

Good cosmetic results were reported during follow up. In fact, cosmetic excellency is an advantage of the minilaparotomy incision. This small suprapubic incision should be closed properly, otherwise may be complicated by Reichter hernia ${ }^{(34)}$.

In our experience, Laparotomy should be carried out in cases of severe haemorrhage with shock (haemodynamic instability), a condition supported by evidence ${ }^{(9,35)}$. In other conditions as cases with large haematocele difficult to evacuate laparoscopically, if ectopic pregnancy is surrounded or hidden by dense adhesions, cases showing gross obesity with difficult access and finally in all cases of comual pregnancy laparotomy is also recommened by many authors $(7,8,11,16,17,22,23)$.

\section{CONCLUSIONS}

In our experience, salpingectomy carried out by laparoscopic directed minilaparotomy enjoys all the advantages of minimally invasive surgery including good cosmetic results, reduced postoperative analgesia requirements and a quicker return of patients to their normal activities. With respect to these, it competes favourably with both laparoscopic salpingectomy by triple-loop 
technique and bipolar electrosurgical one. However, it is more cost effective than the former and more safe than the latter. Also training of surgeons and acquisition of the necessary skills takes shorter that for other techniques.

Salpingectomy carried out by Laparoscopic directed minilaparotomy for the management of disturbed ectopic ampullary pregnancy in haemodynamically stable patients is a simple, safe, versatile and cost effective technique. It may be of benefit and could be offered as an alternative option in circumstances with limited resources and when electrosurgery is not preferred or the electrosurgical unit is out of function.

\section{REFERENCES}

1- Centers for Disease Control and Prevention. cetopic pregnancy-United States, 1990-1992. NMWR I: 49, 1995.

2- Damario MA, Rock JA. Ectopic Pregnancy. In: ROCk JA, Jones HW, Eds. The Linde's Operative Gynecology, $9^{\text {th }}$ edition. Lippincott Williams and Wilkins. 2003: 507.

3- Hibbard BM, editor. Report on Confidential Enquiries into Maternal Deaths int he United Kingdom 1988-1990. london: HMSO 1994; p. 61-67.

4- Lewis G. Drife J, editors. Why Mothers Die 1997-1999. The Fifth Report of th Confidential Enquiries into Maternal Deaths in the United Kingdom. London: RCOG Press; 2001.

5- I.ewis G, Drife J, editors. Why Mothers Die 2000-2002. The Sixth Report of the Confidential Enquiries into Maternal Deaths in the United Kingdom. London: RCOG Press; 2004.

6- Ashis S, Diana H. F. Nonsurgical diagnosis and management of ectopic pregnancy. The Obstetrician and Gynaecologist 2003, 1: 29-33.

7- Gomel V, Taylor PJ. Tubal pregnancy. In: Gomel V, Taylor PJ, Eds. Diagnostic and Operative gynaecologic laparoscopy. Mosby-Year Book, Inc. 1995: 157-168.

8- Gordon AG, Taylor PJ. Simple laparoscopic surgery. In: gordon AG, Taylor PJ, Eds. Pracical laparoscopy. Blackwell Scientific Publications Oxford, London. 1993: 72-75.

9- Royal College of Obstctricians and Gynaccologists. The management of tubal pregnancy. Guideline No. 21. London: RCOG Press; 2004.

10- Mettelr L, Semm K: Management of ectopic pregnancy: a shift from laparotomy to pelviscopy. Int J Fertil 1988; 33: 389-392.

11- Donncz J, Nisolle M: Laparoscopic treatment of ampullary tubal pregnancy. J Gynecol Surg 1989; 5 : 157-162.

12- Semm K: Operative manual for endoscopic abdominal surgery. Ycar Book Mcdical Publishers, Inc. Chicago, 1987.

13- Gomel V. Taylor PJ, Yuzpe $\Lambda$ A. Laparoseopy and hysteroscopy in gynaccologic practice. Year Book Medical Publishers, Inc. Chicago, 1986.

14- Namnoum A B, Murphy A A. Diagnostic and Operative Laparoscopy. In: Rock JA, Jones HW, Eds. TE LINDE's Operative Gynccology, $9^{\text {th }}$ edition. Lippincott Williams and Wilkins. 2003: 372.

15- Silva PD, Schaper AM, Rooney B: Reproductive outcome after 143 Laparoscopic procedures for ectopic pregnancy. Obstet Gynecol Scand 1993; 81: $710-715$

16- Zouves C, Urman B, Gomel V. Laparoscopic surgical treatment of tubal pregnancy. A safe, effective alternative to laparotony, $\mathrm{K}$ Reprod $\mathrm{Med}$ 1992; 37: 205.209.

17- Murphy AA, Nager CW, Whjek JJ. Operative Laparoscopy versus laparotomy for the management of ectopic pregnancy: a prospective trial, Fertil Steril. 1992; 47: 1180-1185.

18- Clausen I. Conservative versus radical surgery for tubal pregnancy. Acta Obstet Gynecol Scand 1996; 75: 8-12.

19- Mole BW, Hajenius PJ, Engelsbel S, Ankum WM, Hemrika DJ, van der Veen $F$, et al. Is conservative 
surgery for tubal pregnancy preferable to salpingectomy? An economic analysis. Br J Obstet Gynaecol 1997; 104: 834-839.

20- Parker J, Bisits A. Laparoscopic surgical treatment of ectopic pregnancy: salpingectomy or salpingostomy? Aust N Z J Obstet Gynaecol 1997; 37: $115-117$.

21- Tulandi T, Saleh A. Surgical management of ectopic pregnancy. Clin Obstet Gynecol 1999, 42: 31-38.

22- Sowter M, Frappell J. The role of laparoscopy in the management of ectopic pregnancy. rev Gynaecol Practice 2002; 2 : 73-82.

23- Spira JN, Bouyer J, Pouly J, Germain E, Coste J, Cuvelier AB, ct al. Fertility after ectopic pregnncy: first results of a population-based cohort study in Fracne. Hum Reprod 1996; 11: 99-104.

24- Mol B, Matthijsse H, Tinga D, Huynh T, Hajenius $P$, Ankum $W$, et al. Fertility after conservative and radical surgery for tubal pregnancy. Hum Reprod 1998; 13: 1804-1809.

25- Bangsgard N, Lund C, Ottesen B, Nilas L. Improved fertility following conservative surgical treatment of ectopic pregnancy. $\mathrm{Br} \mathrm{J}$ Obstet Gynaecol 2003; $110: 765-770$.

26- Kelley R, Martin S, Strickler R. Delayed hemorrhage in conservative surgery for ectopic pregnancy. Am J Obstet Gynecol 1979; 133: 225-226.

27- Hajenius P, Mol B, Ankum W, Van der Veen F, Bossuyt P, Lammes F. Clearance curves of serum human chorionic gonadotrophin for the diagnosis of persistent trophoblast. Hum Reprod 1995; 10 : $683-687$.

28- Lundorff P, Hahlin M, Sjblom P, Lindblom B. Persistent trophoblast after conservative treatment of cctopic pregnancy: prediction and detection. Obstet Gynecol 1991; 77: 129-133.

29- Kcmmann E. trout S, Garcia A. Can We predict patients at risk for persistent ectopic pregnancy after laparoscopic salpingotomy? J Am Assoc Gynecol Laparose 1994; 1: 122-126.

30- Report of RCOG Working Party on Training in Gynaecological Endoscopic Surgery, RCOG Press, London 1994.

31- Gomel V. Reconstructive Tubal Surgery. In: Rock JA, Jones HW, Eds. TE LINDE's Operative Gynecology, $9^{\text {th }}$ edition. Lippincott Williams and Wilkins. 2003: 559.

32- Cooray H, Harilall M, Farquahar C. A six year audit of the management of ectopic pregnancy. Aust $\mathrm{N} \mathrm{Z}$ J Obstet Gynaecol 2002; 42: 538-542.

33- Mohamed H, Maiti S, Phillips G. Laparoscopic management of ectopic pregnancy: a 5-year experience. J Obstet Gynecol 2002; 22: 411-414.

34- Konje JC. Short Essays. MCQ \& OSCEs for MRCOG Part 2, A Comprehensive Guide. Arnold, a member of the Hodder Headline Group, London. 2003: $359-360$

35- Mascarenhas L J. Problems in Early Pregnancy. In: Luesely DM, Baker PN. Eds. Obstetrics and Gynaecology, An Evidence-base d text for MRCOG. Arnold, A member of the Hodder Headline Group, London. 2004: 6060-610. 
Table I : Comparison of the demographic data of the studied patients $(N=46)$

\begin{tabular}{|c|c|c|c|c|c|c|}
\hline \multirow[t]{2}{*}{ Variable } & \multicolumn{2}{|c|}{$\begin{array}{l}\text { Laparoscopic } \\
\text { directed } \\
\text { minilaparotomy } \\
\quad \mathrm{N}=22\end{array}$} & \multicolumn{2}{|c|}{$\begin{array}{l}\text { Triple loop } \\
\text { technique } \\
\quad N=13\end{array}$} & \multicolumn{2}{|c|}{$\begin{array}{c}\text { Bipolar } \\
\text { electrosurgery } \\
N=11\end{array}$} \\
\hline & Mean \pm SD & Range & Mean \pm SD & Range & Mean $\pm S D$ & Range \\
\hline Age (years) * & $26.65 \pm 2.44$ & $22-35$ & $26.54 \pm 2.88$ & $23-34$ & $26.94 \pm 2.92$ & $22-35$ \\
\hline Gravidity * & $4 \pm 1$ & $1-6$ & $4 \pm 1$ & $1-6$ & $4 \pm 1$ & $1-6$ \\
\hline Parity $^{*}$ & $3 \pm 1$ & $0-5$ & $3 \pm 1$ & $0-5$ & $3 \pm 1$ & $0-5$ \\
\hline Weight (Kgm) ${ }^{*}$ & $83.25 \pm 3.42$ & $62-95$ & $83 \pm 3.33$ & $63-94$ & $83.45 \pm 3.67$ & $63-95$ \\
\hline Height $(\mathrm{cm})^{*}$ & $163.65 \pm 3.62$ & $155-172$ & $164.25 \pm 3.95$ & $156-173$ & $163.85 \pm 3.74$ & $155-170$ \\
\hline $\begin{array}{l}\text { Body Mass Index * } \\
\text { BMI = } \\
\text { Weight }(\mathrm{Kgm}) / \text { Height } \\
(\mathrm{m})^{2}\end{array}$ & $27.6 \pm 2.24$ & $21-32$ & $27.2 \pm 2.87$ & $22-32$ & $27.9 \pm 2.35$ & $21-31$ \\
\hline
\end{tabular}

$\mathrm{SD}=$ Standard deviation

All differences were statistically insignificant $(* \mathrm{P}>0.05)$

Table II : Comparison between the laparoscopic directed minilaparotomy group and the other two groups concerning operative time, length of hospital stay

\begin{tabular}{|l|c|c|c|c|c|c|}
\hline \multicolumn{1}{|c|}{ Variable } & \multicolumn{2}{|c|}{$\begin{array}{c}\text { Laparoscopic } \\
\text { directed } \\
\text { minilaparotomy } \\
\mathbf{N = 2 2}\end{array}$} & \multicolumn{2}{c|}{$\begin{array}{c}\text { Triple loop } \\
\text { technique } \\
\mathbf{N = 1 3}\end{array}$} & \multicolumn{2}{c|}{$\begin{array}{c}\text { Bipolar } \\
\text { electrosurgery } \\
\mathbf{N}=11\end{array}$} \\
\hline & Mean \pm SD & Range & Mean \pm SD & Range & Mean \pm SD & Range \\
\hline $\begin{array}{l}\text { Operative time } \\
\text { (minutes) }\end{array}$ & $41.95 \pm 1.62$ & $35-45$ & $42.25 \pm 1.12$ & $38-50$ & $42.99-1.31$ & $40-55$ \\
\hline $\begin{array}{l}\text { Length of hospital } \\
\text { stay (hours) }\end{array}$ & $17.8 \pm 1.3$ & $15-21$ & $18 \pm 1.5$ & $16-22$ & $18.3 \pm 1.4$ & $17-23$ \\
\hline
\end{tabular}

* Calculated from start of anaesthesia

** Calculated from termination of procedure till discharge. all differences were statistically insignificant (\# P > 0.05) 


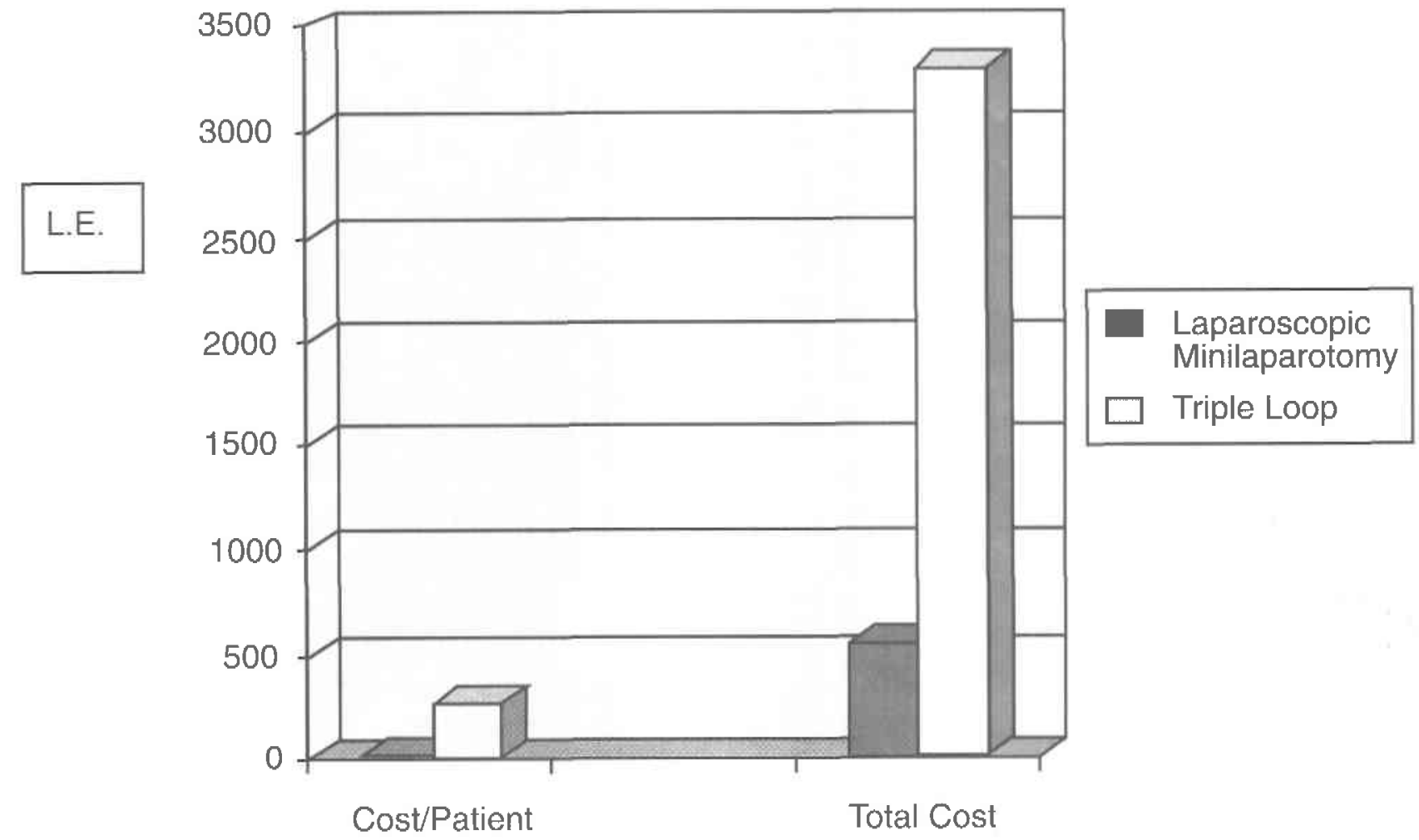

Fig. 1. Comparison of cost per patient and total cost calculated in Egyptian pounds (L. E.) between laparoscopic directed minilaparotomy and triple-loop technique. 